\title{
Diagnóstico do contexto de trabalho de creches-escola municipais
}

\section{Diagnosis of the work context in municipal school-day care centers}

\section{Diagnóstico del contexto laboral de las guarderías-escuela municipales}

\author{
Schmidt, Maria Luiza Gava1 (Assis, SP, Brasil) \\ ORCID ID: http://orcid.org/0000-0002-3296-7238 \\ Santos, Larissa Prato ${ }^{2}$ (Assis, SP, Brasil) \\ Orcid: https://orcid.org/ 0000-0002-3556-3853 \\ Piffer, Letícia ${ }^{3}$ (Assis, SP, Brasil) \\ ORCID ID: https://orcid.org/ 0000-0002-6576-0778 \\ Tonon, Venâncio Paiola ${ }^{4}$ (Assis, SP, Brasil) \\ ORCID ID: https://orcid.org/0000-0001-8476-3811 \\ Massuda Junior, João ${ }^{5}$ (Campo Grande, MS, Brasil) \\ ORCID ID: https://orcid.org/0000-0003-0523-6285. \\ Areosa, João ${ }^{6}$ (Lisboa, Portugal) \\ ORCID ID: https://orcid.org/0000-0001-5112-1521
}

\begin{abstract}
Resumo
Trata-se de um relato de experiência de estágio em Psicologia no campo da saúde do trabalhador que teve como objetivo diagnosticar aspectos das condições de trabalho, da organização do trabalho e das relações socioprofissionais de duas creches-escola municipais. Foi realizado um estudo transversal que utilizou a Escala de Avaliação do Contexto de Trabalho (EACT) com 39 trabalhadores, sendo 19 de uma creche e 20 da outra. O resultado médio obtido para os fatores "Organização do Trabalho" e "Condições de Trabalho" indicou resultado "Crítico" em ambas as creches, sinalizando a existência de uma situação de alerta que demanda a implementação de ações imediatas no curto e médio prazo para que melhorias sejam alcançadas. O fator relações socioprofissionais obteve resultado médio considerado satisfatório para a creche-escola 01 e crítico para a creche-escola 02 . A escala EACT, em ambas as unidades educacionais, apresentou consistência interna e inexistência de redundância, uma vez que o Alpha de Cronbach obtido variou de 0,78 a 0,82 na creche-escola 01 e de 0,69 a 0,81 na creche-escola 02. Concluiu-se que o contexto de ambas as creches não é totalmente favorável, existindo a necessidade de intervenções a fim evitar danos à saúde dos trabalhadores.
\end{abstract}

Palavras-chave: Psicologia do trabalho. Serviço de creche escolar. Saúde mental.

\section{Abstract}

This is a report on a Psychology internship experience in the worker's health field that aimed to diagnose aspects of working conditions, work organization and socio-professional relations of two municipal school-day care centers. A cross-sectional study was carried out using the Assessment Scale of Work Context (ASWC) with 39 workers, 19 from one day care center and 20 from the other. The average result obtained for the factors "Work Organization" and "Work Conditions" indicated a "Critical" result in both day care centers, signaling the existence of an alert situation that demands the implementation of immediate actions in the short and medium term for improvements to be achieved. The socioprofessional relations factor obtained an average result considered satisfactory for school-day care center 1 and critical for school-day care center 2. The ASWC scale in both educational units showed internal consistency and no redundancy since the Cronbach's Alpha obtained ranged from 0.78 to 0.82 in school-day care center 1 and from 0.69 to 0.81 in school-day care center 2 . It was concluded that the

\footnotetext{
1 Docente do Departamento de Psicologia Social, Faculdade de Ciências e Letras - Unesp, Câmpus de Assis/SP. mlschmidt@uol.com.br

2 Bolsista de Iniciação Científica FAPESP no campo da Saúde do Trabalhador. larissa.prato@unesp.br

${ }^{3}$ Graduanda em Psicologia na Universidade Estadual Paulista, e Coordenadora de gestão de pessoas da Empresa Júnio Humanus. leticia.piffer@unesp.br

${ }^{4}$ Graduanda em Psicologia na Universidade Estadual Paulista. paiola.tonon@unesp.br

${ }^{5}$ Professor no Instituto Federal de Mato Grosso do Sul (IFMS) e Membro do Laboratório de Saúde Mental e Qualidade de Vida no Trabalho (UCDB/CNPq). joao.massuda@ifms.edu.br

${ }^{6}$ Professor Adjunto na Escola Superior de Ciências Empresariais (ESCE-IPS), Portugal. joao.s.areosa@gmail.com
} 
context of both day care centers is not entirely favorable, and there is a need for interventions in order to avoid damage to the workers' health.

Keywords: Psychology of work. School childcare service. Mental health.

\section{Resumen}

Se trata de un informe de experiencia de prácticas en Psicología en el ámbito de la salud del trabajador que tuvo como objetivo diagnosticar aspectos de las condiciones laborales, de la organización laboral y de las relaciones socioprofesionales de dos guarderías-escuela municipales. Se realizó un estudio transversal que utilizó la Escala de Evaluación del Contexto de Trabajo (EACT) con 39 trabajadores, 19 de una guardería y 20 de la otra. El resultado promedio obtenido para los factores "Organización Laboral" y "Condiciones de Trabajo" indicó resultado "Crítico" en ambas guarderías, señalando la existencia de una situación de alerta que exige la implementación de acciones inmediatas en el corto y mediano plazo para que se logren mejoras. El factor relaciones socioprofesionales obtuvo un resultado promedio considerado satisfactorio para la guardería-escuela 1 y crítico para la guardería-escuela 2. La escala EACT, en ambas unidades educativas, presentó consistencia interna y ausencia de redundancia, ya que el Alpha de Cronbach obtenido osciló entre 0,78 y 0,82 en la guardería-escuela 1 y entre 0,69 y 0,81 en la guardería-escuela 2 . Se concluyó que el contexto de ambas guarderías no es totalmente favorable, siendo necesario intervenir para evitar daños a la salud de los trabajadores.

Palavras-clave: Psicología del trabajo. Servicio de guardería escolar. Salud mental.

\section{Introdução}

A educação infantil como direito foi reconhecida na Constituição Federal (BRASIL, 1988), sendo efetivada como primeira etapa da educação básica (BRASIL, 1996). A partir de então, os marcos legais da educação das crianças passaram por várias mudanças significativas (NASCIMENTO, 2009). Nesse contexto, “[...] atualmente a Educação Infantil engloba creches, que atendem crianças de zero a três anos, e pré-escolas, que atendem crianças de quatro a seis anos" (MARTINS; VERÍSSIMO, 2006, p. 488).

Ao considerar-se o cotidiano de trabalho em creche, esse ambiente ocupacional atenta para diversas situações potencialmente geradoras de estresse ocupacional (BERALDO; CARVALHO, 2006). A presença de intenso sofrimento psíquico relacionado ao trabalho em trabalhadores que atuam nas atividades da atual política pública voltada à educação infantil no Brasil também tem sido apontada nos estudos de Paparelli et al. (2007).

De acordo com Silva, Souza e Santos (2019), pelo fato de os trabalhadores estarem imersos em contexto de precarização laboral e de relações hierárquicas autoritárias, poucas têm sido as oportunidades para uma reflexão mais aguda sobre os processos de trabalho. Dentre os fatores que podem comprometer a saúde nestes contextos laborais, especialmente entre os profissionais que atuam como monitoras foram identificados a "[...] precarização, sobrecarga e intensificação do trabalho; 
gestão, política e conflitos; diferenças entre o trabalho de professoras e monitoras; e educação, saúde e cuidado" (SILVA; SOUZA; SANTOS, 2019, p. 15).

Beraldo e Carvalho (2006) no intuito de melhor conhecer o trabalho de educadoras de creche investigaram a percepção de um grupo destas trabalhadoras sobre os fatores de satisfação, de insatisfação e de estresse, estratégias de enfrentamento (coping) em situações estressantes e outros tópicos, e identificaram que:

[...] a criança é a fonte principal de satisfação no trabalho, embora também gere preocupações. A insatisfação deriva principalmente da desvalorização social do trabalho, expressa cotidianamente nas interações com as famílias das crianças. Relações interpessoais respondem prioritariamente tanto às experiências de satisfação quanto de estresse. (BERALDO; CARVALHO, 2006, p. 35)

Em pesquisa de revisão sistemática sobre trabalho em creche Vasconcelos, Santana e Borges (2015, p. 83) observaram que "a produção científica nacional sobre o trabalho e a saúde mental da educadora de creche não é vasta, sobretudo se considerar a relação entre essa temática e a Psicologia Social do Trabalho".

Estudos dos processos de saúde e doença relacionados ao trabalho são relevantes para o fortalecimento das políticas de prevenção de adoecimento e promoção da saúde dos trabalhadores. Desse modo, foi desenvolvido um projeto de estágio com o objetivo de diagnosticar aspectos das condições de trabalho, da organização do trabalho e das relações socioprofissionais de duas creches-escola do âmbito municipal, visando apresentar proposições interventivas em aspectos do contexto de trabalho que possam comprometer a saúde dos trabalhadores.

\section{Método}

Trata-se de uma atividade de estágio profissionalizante, com o intuito exclusivamente de ensino, desenvolvido por alunos de graduação em Psicologia sob supervisão, sendo o procedimento ético deste diagnóstico realizado com base no parágrafo único, artigo VIII da Resolução ํo 510 sobre a Ética na Pesquisa na área de Ciências Humanas e Sociais do Conselho Nacional de Saúde (BRASIL, 2016). Não necessitando ser registrada nem avaliada pelo sistema CEP/CONEP conforme 
disposto no parágrafo único desta resolução.

O contato com os participantes para coleta de dados foi realizado individualmente nas dependências da instituição em sala com infraestrutura adequada, com o devido consentimento formal da Secretaria de Educação do município. O tempo de coleta de dados foi de no mínimo quarenta minutos e no máximo uma hora. Foi utilizado para a coleta a Escala de Avaliação do Contexto de Trabalho (EACT), validada por Ferreira e Mendes (2008). Os dados foram analisados quantitativamente. Os respondentes foram convidados a participar pelo livre e espontâneo interesse, sendo mantido o anonimato dos participantes.

\subsection{Participantes}

O diagnóstico foi realizado no período de abril a novembro do ano de 2019, a pedido da Secretaria Municipal de Educação de um município com aproximadamente 14 mil habitantes, localizado no interior do estado de São Paulo. $\mathrm{Na}$ fase de coleta de dados o município possuía duas creches-escola (denominadas no texto, respectivamente, como creche-escola 01 e creche-escola 02). A crecheescola 01 atendia 156 alunos com um quadro funcional composto por 24 trabalhadores atuantes nas seguintes categorias profissionais: nove professores; cinco agentes de apoio; um diretor escolar; um coordenador pedagógico; dois agentes escolares; três auxiliares de serviços gerais; dois funcionários de serviços gerais e uma merendeira. Desse quadro, 19 profissionais participaram da coleta de dados. Entre os funcionários participantes da creche-escola $01,94,7 \%$ eram do gênero feminino. Questionados acerca de sua idade, 26,3\% responderam ter entre 21 e 30 anos, $21,1 \%$ entre 31 e 40 anos, $36,8 \%$ entre 41 e 50 anos e 15,8\% entre 51 e 60 anos. Em relação ao grau de escolaridade, 10,5\% reportaram possuir o Ensino Fundamental Incompleto, 5,3\% Ensino Fundamental Completo, 5,3\% Ensino Médio Incompleto, 10,5\% Ensino Superior Completo, 15,8\% Especialização e 15,8\% Pósgraduação.

A creche-escola 02 atendia 126 alunos com o quadro funcional composto por 22 trabalhadores, sendo: dez professores; quatro agentes de apoio educacional; um diretor escolar; um coordenador pedagógico; dois agentes escolares; quatro funcionários de serviços gerais. Desse quadro, 20 profissionais participaram do 
diagnóstico. Entre os funcionários participantes da creche-escola 02, 81,8\% eram do gênero feminino, 22,7\% tinham entre 21 e 30 anos, 36,4\% entre 31 e 40 anos, $22,7 \%$ entre 41 e 50 anos, 4,5\% entre 51 e 60 anos e 4,5\% com mais de 60 anos. Em relação ao grau de escolaridade, 13,6\% informaram possuir Ensino Fundamental Completo, 13,6\% Ensino Médio Completo, 22,7\% Ensino Superior Completo e 40,9\% possuíam Pós-Graduação.

Dentre os funcionários de ambas as creches-escola foram excluídos os estagiários (três da creche-escola 01 e cinco da creche-escola 02), por não pertencerem ao regime de contrato de trabalho e atuarem apenas em atividades de estágio. Os demais trabalhadores participaram conforme disponibilidade para preenchimento do instrumento.

\subsection{Instrumento}

Para coleta de dados foi utilizada a Escala de Avaliação do Contexto de Trabalho (EACT), validada por Ferreira e Mendes (2008). Esta escala possibilita a análise de três dimensões do contexto de trabalho: Organização do Trabalho, Condições de Trabalho e Relações Socioprofissionais. Este instrumento é composto por 31 questões com respostas em escala Likert que variam de 1 a 5 pontos.

Neste instrumento, o tratamento dos dados é realizado mediante estatística descritiva (frequências, média e desvio padrão). Por ser uma escala do tipo Likert, apresenta as seguintes opções de respostas: 1 = nunca; 2 = raramente; 3 = às vezes; 4 = frequentemente; 5 = sempre. A distribuição dos fatores na escala é distribuída nas três dimensões sendo 11 referentes à dimensão Organização do Trabalho, 10 da dimensão Condições de Trabalho e 10 da dimensão Relações Socioprofissionais.

A prática de estágio também envolveu conversas informais com os trabalhadores e servidores da Secretaria Municipal de Educação, bem como a observação dos diferentes ambientes de trabalho (sala de aula, cozinha e sala administrativa, por exemplo). As atividades foram orientadas mediante supervisões semanais.

\subsection{Análise dos resultados}

A análise da EACT foi realizada por meio de tratamento estatístico em nível 
descritivo, utilizando-se o software SPSS (Statistical Package for the Social Sciences) - versão 25 , de acordo com a orientação dos autores do instrumento, seguindo a definição da média bruta em três parâmetros, cujos resultados indicam o grau de possibilidade de o contexto de trabalho impactar a saúde dos trabalhadores, a saber:

- Acima de 3,7 = resultado negativo, grave. Indica que o contexto de trabalho possibilita de forma grave o adoecimento do profissional.

- Entre 2,3 e 3,69 = resultado moderado, crítico. Indica que o contexto de trabalho favorece moderadamente o adoecimento do profissional.

- Abaixo de 2,29 = resultado positivo, satisfatório. Indica que o contexto de trabalho favorece a saúde do profissional.

\section{Resultados}

A análise dos dados coletados, por meio da EACT, indicou que os resultados observados apresentam uma distribuição normal, dado que os indicadores relativos à assimetria e curtose, para as diferentes escalas, encontram-se dentro dos parâmetros de variação ( \pm 2 ) propostos por Field (2009) e Gravetter e Wallnau (2014). Este resultado permite que sejam utilizadas métricas da estatística paramétrica para a análise dos resultados, ainda que o tamanho da amostra deste estudo seja reduzido.

As escalas avaliadas pela EACT, em ambas as unidades educacionais estudadas, apresentaram adequada consistência interna e inexistência de redundância (STREINER, 2003; STREINER; NORMAN; CAIRNEY, 2015; TAVAKOL; DENNICK, 2011), uma vez que o Alpha de Cronbach obtido variou de 0,78 a 0,82 na creche-escola 01 e 0,69 a 0,81 na creche-escola 02. 
Tabela 1. Estatística descritiva referente aos fatores da EACT na amostra pesquisada

\begin{tabular}{clccccc}
\hline \multicolumn{1}{c}{ Fatores } & Média & $\begin{array}{c}\text { Desvio- } \\
\text { padrão }\end{array}$ & Assimetria & Curtose & $\begin{array}{c}\text { Alpha de } \\
\text { Cronbach }\end{array}$ \\
\hline Creche- & Organização do trabalho & 2,61 & 0,73 & 0,41 & $-0,58$ & 0,81 \\
escola 01 & Relações socioprofissionais & 2,02 & 0,72 & 0,34 & $-0,84$ & 0,82 \\
$(\mathrm{n}=19)$ & Condições de trabalho & 2,35 & 0,71 & 0,35 & $-0,67$ & 0,78 \\
\hline Creche- & Organização do trabalho & 3,20 & 0,57 & 0,64 & $-0,86$ & 0,69 \\
escola 02 & Relações socioprofissionais & 2,31 & 0,63 & $-0,09$ & $-0,98$ & 0,76 \\
$(\mathrm{n}=20)$ & Condições de trabalho & 2,41 & 0,68 & 0,38 & $-0,35$ & 0,81 \\
\hline
\end{tabular}

O resultado médio obtido para o fator Organização do Trabalho indica que este elemento merece atenção em ambas as organizações pesquisadas, tendo em vista que os parâmetros básicos para a interpretação dos resultados da EACT classificam o resultado apresentado como crítico, sinalizando a existência de uma situação de alerta que demanda a implementação de ações imediatas no curto e médio prazo para que melhorias sejam alcançadas (Tabela 1).

Os elementos que mais influenciaram a avaliação da Organização do Trabalho na creche-escola 01 foram: a forte cobrança por resultados, a rigidez das normas para execução das tarefas, o número insuficiente de pessoas para a execução das tarefas e a expectativa pelo alcance de resultados fora da realidade. Já na crecheescola 02, foi observado que a pressão para o cumprimento de prazos, a forte cobrança por resultados, a rigidez das normas e a falta de tempo para o descanso foram os fatores que mais contribuíram para a avaliação observada.

Em relação ao fator Condições de Trabalho, observou-se que o resultado médio também indicou ser este um elemento crítico nas duas instituições participantes deste estudo, de acordo com os parâmetros básicos para a interpretação dos resultados da EACT. No entanto, é importante salientar que os resultados identificados se encontram próximos ao limite estabelecido pela escala para que este pudesse ser classificado como satisfatório (Tabela 1).

A precariedade das condições e instrumentos de trabalho, instrumentos de trabalho insuficientes, materiais de consumo insuficientes e condições de trabalho que 
oferecem risco à segurança dos trabalhadores foram os fatores que mais influenciaram a avaliação das condições de trabalho em ambas as creches-escolas investigadas.

Por fim, o fator Relações Socioprofissionais obteve um resultado médio considerado satisfatório para a creche-escola 01 e crítico para a creche-escola 02 , segundo os parâmetros básicos para a interpretação dos resultados da EACT. Tal resultado positivo para a creche-escola 01 é importante, pois reflete o compromisso da organização com os trabalhadores e denota os impactos positivos de um ambiente de trabalho em que há uma definição clara das atividades a serem desempenhadas, uma distribuição justa das tarefas, uma comunicação satisfatória, uma integração entre os trabalhadores e inexistem disputas profissionais (Tabela 1).

A análise detalhada das relações socioprofissionais na escola-creche 02 indica que os elementos de maior peso para a avaliação crítica observada foram: a não participação dos trabalhadores nas decisões, dificuldades de comunicação entre chefia e subordinado e entre os próprios trabalhadores, falta de suporte da chefia para o desenvolvimento profissional de suas equipes e o difícil acesso às informações necessárias para a realização do trabalho.

Apesar dos resultados médios classificarem as organizações estudadas em categorias estáticas quanto à organização do trabalho, condições de trabalho e relações socioprofissionais, a amostra estudada possui indivíduos que percebem tais fatores de diferentes maneiras, sendo esta distribuição apresentada por meio da Tabela 2.

Tabela 2. Distribuição de frequência referente aos fatores da EACT na amostra pesquisada

\begin{tabular}{clccc}
\hline & \multicolumn{1}{c}{ Fatores } & Satisfatório (\%) & Crítico (\%) & Grave (\%) \\
\hline Creche- & Organização do trabalho & 31,6 & 57,9 & 10,5 \\
escola 01 & Relações socioprofissionais & 73,7 & 26,3 & - \\
$(\mathrm{n}=19)$ & Condições de trabalho & 57,9 & 36,8 & 5,3 \\
\hline Creche- & Organização do trabalho & - & 80,0 & 20,0 \\
escola 02 & Relações socioprofissionais & 50,0 & 50,0 & - \\
$(\mathrm{n}=20)$ & Condições de trabalho & 50,0 & 50,0 & - \\
\hline
\end{tabular}

Fonte: Os autores 
Também foram analisadas as possíveis associações entre as variáveis demográficas pesquisadas e os fatores componentes da EACT, sendo identificada uma correlação estatisticamente significativa e positiva entre os resultados da escala Organização do Trabalho e as unidades educacionais pesquisadas $(\rho=0,435 ; p$ valor $=0,006)$, Organização do Trabalho e escolaridade $(\rho=0,320 ; p$ valor $=0,047)$ e Condições de Trabalho e tempo no cargo $(\rho=0,328 ; p$ valor $=0,044)$. Foi observada ainda uma correlação estatisticamente significativa e negativa entre as Condições de Trabalho e a idade dos respondentes $(\rho=0,361 ; p$ valor $=0,024)$.

As associações identificadas apontam que trabalhadores com maior escolaridade reportaram uma avaliação mais negativa de suas condições de trabalho, assim como os trabalhadores com mais tempo de serviço nas instituições também informaram perceber piores condições de trabalho. A análise da associação entre idade e condições de trabalho identificou que trabalhadores mais novos perceberam piores condições de trabalho.

Para melhor compreender a associação identificada entre a escala Organização do Trabalho e as unidades educacionais estudadas, foi realizado o teste t para comparação dos escores médios obtidos nas três escalas avaliadas pelo instrumento EACT. Os resultados indicaram a existência de uma diferença, estatisticamente significativa, entre os escores médios obtidos pela creche-escola 01 e creche-escola 02, para o fator Organização do Trabalho. Os escores médios indicaram que unidade educacional 01 obteve um resultado mais positivo quando comparado ao indicador apresentado pela unidade educacional 02 , ainda que ambos os resultados se encontrem no mesmo intervalo de classificação utilizado nos parâmetros básicos para a interpretação dos resultados da EACT (Tabela 3).

Para melhor compreender as diferenças entre os escores médios apresentados por ambas as creches estudas, nos diferentes fatores da EACT, foi analisado o tamanho do efeito por meio do cálculo do $D$ de Cohen. Os resultados apresentados indicam uma grande diferença entre os escores obtidos por ambas as instituições para o fator organização do trabalho, uma pequena diferença para o fator relações socioprofissionais e uma diferença insignificante para o fator condições de trabalho. Tal análise complementa os resultados obtidos por meio do teste t para 
comparação das médias obtidas no EACT.

Tabela 3. Teste t para comparação das médias obtidas no EACT e teste D de Cohen para cálculo do tamanho do efeito para as duas unidades educacionais investigadas

\begin{tabular}{llllc}
\hline \multicolumn{1}{c}{ Fatores } & Média & Desvio-padrão & P valor & D de Cohen \\
\hline $\begin{array}{l}\text { Organização do trabalho } \\
\text { Creche-escola 01 }\end{array}$ & 2,61 & 0,73 & & \\
Creche-escola 02 & 3,20 & 0,57 & 0,008 & 0,90 \\
\hline $\begin{array}{l}\text { Relações socioprofissionais } \\
\text { Creche-escola 01 }\end{array}$ & 2,02 & 0,72 & 0,781 & 0,43 \\
Creche-escola 02 & 2,31 & 0,63 & & \\
\hline Condições de trabalho & & & & \\
Creche-escola 01 & 2,35 & 0,71 & 0,189 & 0,09 \\
Creche-escola 02 & 2,41 & 0,68 & & \\
\hline
\end{tabular}

Fonte: Os autores

Por fim, a análise da associação entre as escalas avaliadas pelo EACT indicou ainda a existência de uma correlação estatisticamente significativa, moderada e positiva entre os fatores Organização do Trabalho e Condições de Trabalho ( $\rho=0,591 ; p$ valor $=0,000)$, Organização do Trabalho e Relações Socioprofissionais $(\rho=0,575 ; p$ valor $=0,000)$ e Condições de Trabalho e Relações Socioprofissionais $(\rho=0,596 ; p$ valor $=0,000)$ em ambas as instituições estudas.

\section{Discussão}

As repercussões da organização do trabalho sobre o aparelho psíquico dos trabalhadores foram evidenciadas na década de 1980 pelo trabalho de Christophe Dejours, com a publicação na França de Travail: usure mentale. Essai de psychopatologie, traduzido no Brasil sob o título "A loucura do trabalho: estudo de psicopatologia do trabalho", em 1987. Nesta obra, o autor designa por organização do trabalho os aspectos da divisão do trabalho, conteúdo da tarefa, modalidades de comando, relações de poder, questões de responsabilidade etc., presentes nas relações de trabalho que podem ser fonte preponderante de sofrimento psíquico, produzindo impactos à saúde mental dos trabalhadores (DEJOURS, 2015). O mundo 
hodierno do trabalho pode ser visto como um dos principais focos do sofrimento humano (AREOSA, 2018).

Esses cenários são constituídos por elementos formais e informais expressos nas práticas de gestão dos contextos laborais que dinamizam seu funcionamento como: regras de produtividade, dispositivos de procedimentos, jornada de trabalho, ritmo das atividades, mecanismos de controle, características das tarefas, entre outros (FERREIRA; MENDES, 2008). No entanto, as atuais técnicas de gestão estão a colocar os trabalhadores sob enorme pressão (GAULEJAC, 2007) e esse contexto faz aumentar as designadas patologias da sobrecarga. Os dados recolhidos em nossa pesquisa, através da EACT, demonstram esses efeitos nos trabalhadores observados. O aumento do estresse, da ansiedade, do medo e da depressão em diversos ambientes laborais ilustram de modo claro a degradação da saúde física e mental. Há uma profunda colonização do corpo e da mente dos trabalhadores que captura sua subjetividade (MENDES, 2018), corrói sua identidade, dilui os laços de solidariedade e, por consequência, inibe a construção de coletivos de trabalho coesos e estruturados. As "novas" técnicas de gestão promovem sociedades de elevado desempenho que, simultaneamente, comprometem a saúde dos trabalhadores (HAN, 2017).

A dinâmica destes aspectos foi embasada por Dejours mediante a teoria por ele denominada de Psicodinâmica do Trabalho, a qual com fundamentação em conceitos psicanalíticos analisa a dinâmica dos processos psíquicos envolvidos na confrontação do sujeito com a realidade de trabalho, mediante as vivências subjetivas e intersubjetivas que permeiam as relações com o trabalho e os processos de regulação psíquica (DEJOURS; ABDOUCHELI; JAYET, 1994). Embora a Psicodinâmica do Trabalho busque compreender os aspectos psíquicos e subjetivos, a partir de uma abordagem qualitativa, métodos quantitativos ganham novas perspectivas neste tipo de investigação (HELOANI; LANCMAN, 2004).

Com dados quantitativos, observamos que aspectos como sobrecarga de trabalho e intensificação do trabalho, decorrente de número reduzido de trabalhadores, obtiveram percentuais mais expressivos nos enunciados da dimensão organização do trabalho, indicando que os trabalhadores nas duas creches estão expostos a aspectos que podem produzir efeitos negativos à saúde psíquica. 
Paralelamente, a intensificação do trabalho está, por regra, associada ao aumento da exploração e da alienação (ROSSO, 2008).

O mal-estar nas relações laborais também se manifesta quando há falta de condições de trabalho, ou seja, quando o ambiente físico apresenta infraestrutura inadequada que gera desconforto (temperatura inadequada, ruído elevado, vibrações etc.), riscos químicos, biológicos, de segurança e ergonômicos (DEJOURS, 2015). Elementos estruturais que expressam a qualidade do posto de trabalho, dos materiais e equipamentos para execução do trabalho (FERREIRA; MENDES, 2008). Os resultados do diagnóstico revelaram instalações inadequadas e falta de recursos para desenvolvimento do trabalho pedagógico junto com as crianças, com prováveis efeitos sobre o trabalho e a saúde dos trabalhadores. Há vários estudo que estabelecem uma correlação entre condições de trabalho inadequadas e degradação da saúde (VARELA et al., 2020).

No que tange aos aspectos das relações socioprofissionais, ou seja, os elementos interacionais presentes no lócus de trabalho que caracterizam a dimensão social como: modos de gestão, comunicação e interação profissional (FERREIRA; MENDES, 2008), verificaram-se possíveis desajustes. Em todos os laços humanos (relações com a hierarquia, supervisão, entre pares) que por serem potencialmente desagradáveis, podem ser fonte de ansiedade (DEJOURS, 2015). Destacamos que na creche-escola 02 , o resultado da média bruta das relações socioprofissionais apontou percentual crítico, sinalizando estado de alerta para os enunciados desta dimensão, por indicar mal-estar e risco de adoecimento dos trabalhadores neste contexto.

\section{Considerações finais}

A Escala de Avaliação do Contexto de Trabalho (EACT) mostrou-se útil, por possibilitar a realização de uma avaliação do contexto de trabalho mediante a percepção dos próprios trabalhadores. O diagnóstico revelou que o contexto de trabalho de ambas as creches não é totalmente favorável à saúde dos trabalhadores, uma vez que a organização do trabalho foi considerada crítica. Mediante os dados emergentes da EACT foi possível identificar que os trabalhadores das crechesescolas avaliam como impróprias a organização e as condições laborais na maioria 
dos aspectos que as definem.

Este diagnóstico se insere em um contexto mais amplo de precarização do trabalho na educação pública brasileira, sobretudo na educação infantil. A pouca visibilidade dos problemas enfrentados no cotidiano das creche-escolas brasileiras é histórico, estando associados a questões como a feminização do trabalho docente, a luta pela ampliação do acesso ao ensino e a defesa da dimensão formativa das creches (SILVA; SOUZA; SANTOS, 2019). Assunção e Oliveira (2009, p. 352) também demonstraram que, no contexto de mudanças organizacionais relacionadas à educação, fatores como a "massificação da educação, a desregulação, a redefinição das tarefas [...] e da fraqueza dos debates sobre essas questões" contribuem com para a intensificação dos trabalhos em contextos educacionais, e consequentemente, trazem prejuízos à saúde dos trabalhadores atuantes nesse cenário.

Os resultados do presente estudo também representaram avanços do conhecimento no campo da saúde do trabalhador, tendo-se em vista a escassez de produções nacionais com esta abordagem em creches. Como limitações, mencionase o tamanho da população estudada e o fato de o diagnóstico ter sido realizado num único município. Assim, sugere-se a realização de investigações, em estudos que abordem estas questões em outras creches municipais.

Os resultados foram apresentados no formato de relatório e entregues à Secretaria de Educação e ao prefeito do município, numa reunião de devolutiva. Foi assegurada também a guarda do material de coleta de dados nos arquivos do Departamento de Psicologia.

A fim de minimizar os problemas evidenciados, foram apresentadas algumas proposições visando melhorias nos contextos de trabalho. Para amenizar os riscos à saúde mental produzidos pelos aspectos da Organização do Trabalho foram destacados: a necessidade de adequação do quadro funcional para o atendimento das demandas e consequentemente redução do ritmo de trabalho, pontuado como intenso para a maioria dos respondentes.

No que tange aos aspectos das Condições de Trabalho, os itens mais pontuados como infraestrutura inadequada e falta de materiais de papelaria e limpeza foram registrados em prioridade de intervenções.

Embora o fator Relações Socioprofissionais não tenha apresentado 
percentuais elevados, foi sugerido também o estabelecimento de critérios conjuntos visando a melhor distribuição das tarefas de modo a evitar conflitos interpessoais em decorrência desta situação.

Espera-se com este diagnóstico contribuir não apenas com os serviços do município com vistas para melhorias nos aspectos da organização e condições de trabalho das creches, mas com a construção do conhecimento em saúde do trabalhado no campo da Psicologia. O estudo forneceu pistas para novas investigações com procedimentos de abordagem qualitativa visando o aprofundamento dos aspectos das três dimensões permitindo trazer à luz informações relativas aos percentuais verificados nos resultados quantitativos.

\section{Referências Bibliográfica}

AREOSA, João. O trabalho como palco do sofrimento. International Journal on Working Conditions, n. 15, p. 81-95, 2018.

ASSUNÇÃO, Ada Ávila.; OLIVEIRA, Dália Andrade. Intensificação do trabalho e saúde dos professores. Educação \& Sociedade, v. 30, p. 349-372, ago. 2009. https://doi.org/10.1590/S0101-73302009000200003

BERALDO, Katharina Elisabeth Arnold; CARVALHO, Ana Maria Almeida. Ouvindo educadoras de creche sobre suas experiências no trabalho. Temas em Psicologia, v. 14, n. 1, p. 35-49, 2006.

BRASIL. Constituição da República Federativa do Brasil de 1988. Diário Oficial da União, Brasília, DF, 5 out. 1988.

BRASIL. Lei ㄲo 9.394, de 20 de dezembro de 1966. Estabelece as diretrizes e bases da educação nacional. Diário Oficial da União, Brasília, DF, 23 dez. 1996.

BRASIL. Ministério da Saúde. Resolução oㅜ 510, de 7 de abril de 2016. O Plenário do Conselho Nacional de Saúde em sua Quinquagésima Nona Reunião Extraordinária, realizada nos dias 06 e 07 de abril de 2016, no uso de suas competências regimentais e atribuições conferidas [...]. Diário Oficial da União, Brasília, DF, 24 maio 2016.

DEJOURS, Christophe. A loucura do trabalho: estudo de psicopatologia do trabalho. 6. ed. São Paulo: Cortez-Oboré, 2015.

DEJOURS, Christophe; ABDOUCHELI, Elizabeth; JAYET, Christian. Psicodinâmica do trabalho: contribuições da escola dejouriana à análise da relação prazer, sofrimento e trabalho. São Paulo: Atlas, 1994. 
FERREIRA, Mário César; MENDES, Ana Magnólia. Contexto de trabalho. In: SIQUEIRA, Mirlene Maria Matias (org.). Medidas do comportamento organizacional: ferramentas de diagnóstico e gestão. Porto Alegre: Artmed, 2008. p. 111-123.

FIELD, Andy. Discovering statistics using SPSS. 3rd ed. London: Sage, 2009.

GAULEJAC, Vincent de. Gestão como doença social: ideologia, poder gerencialista e fragmentação social. São Paulo: Ideias e Letras, 2007.

GRAVETTER, Frederick J.; WALLNAU, Larry B. Essentials of statistics for the behavioral sciences. 8th ed. Wadsworth: Cengage Learning, 2014.

HAN, Byung-Chul. Sociedade do cansaço. Petrópolis: Vozes, 2017.

HELOANI, Roberto; LANCMAN, Selma. Psicodinâmica do trabalho: o método clínico de intervenção e investigação. Production, v. 14, n. 3, p. 77-86, 2004. https://doi.org/10.1590/S0103-65132004000300009

MARTINS, Juliana; VERÍSSIMO, Maria de la Ó Ramalho. Conhecimentos e práticas de trabalhadoras de creches municipais relativos ao cuidado da criança com infecção respiratória aguda. Interface - Comunicação, Saúde, Educação, v. 10, n. 20, p. 487504, 2006. https://doi.org/10.1590/S1414-32832006000200015

MENDES, Ana Magnólia. Desejar, falar, trabalhar. Porto Alegre: Editora Fi, 2018.

NASCIMENTO, Maria Letícia Barros Pedroso. Sociologia da infância e educação infantil: algumas considerações sobre a aproximação entre essas duas áreas na pesquisa sobre a pequena infância. Horizontes, v. 27, n. 2, p. 31-36, 2009.

PAPARELLI, Renata et al. Contribuições da saúde do trabalhador à educação infantil: o sofrimento mental de educadoras de uma creche paulistana. Cadernos de Psicologia Social do Trabalho, v. 10, n. 2, p. 1-15, 2007. https://doi.org/10.11606/issn.1981-0490.v10i2p1-15

ROSSO, Sadi Dal. Mais trabalho!: a intensificação do labor na sociedade contemporânea. São Paulo: Boitempo, 2008.

SILVA, Daniela Almeida de Jesus da.; SOUZA, Katia Reis de; SANTOS, Gideon Borges dos. Trabalho e saúde de professoras e monitoras de creche pública no município de Vitória da Conquista, BA, Brasil. Interface - Comunicação, Saúde, $\begin{array}{llllll}\text { Educação, } & \text { v. 23, } 29 \text { jul. 2019. https://doi.org/10.1590/ }\end{array}$ Interface.180497

SILVA, Daniela Almeida de Jesus; SOUZA, Katia Reis de; SANTOS, Gideon Borges dos. Trabalho e saúde de professoras e monitoras de creche pública no município de Vitória da Conquista, BA, Brasil. Interface - Comunicação, Saúde, Educação, v. 23, e180497, 2019. https://doi.org/10.1590/interface.180497 
STREINER, David L. Starting at the beginning: an introduction to coefficient Alpha and internal consistency. Journal of Personality Assessment, v. 80, n. 1, p. 99-103, 2003. https://doi.org/10.1207/S15327752JPA8001

STREINER, David L.; NORMAN, Geoffrey R.; CAIRNEY, John. Health measurement scales: a practical guide to their development and use. 5th ed. Oxford: Oxford University Press, 2015.

TAVAKOL, Mohsen; DENNICK, Reg. Making sense of Cronbach's alpha. International Journal of Medical Education, v. 2, p. 53-55, 2011. https://doi.org/10.5116/ijme.4dfb.8dfd

VARELA, Raquel et al. Desgaste, condições de vida e trabalho em Portugal: uma perspectiva multidisciplinar. Estudos do Século XX, n. 20, p. 183-210, 2020. https://doi.org/10.14195/1647-8622_20_9

VASCONCELOS, Dalila Castelliano de; SANTANA, Inayara Oliveira de; BORGES, Lucivanda Cavalcante. $O$ trabalho da educadora na creche: uma revisão sistemática. Psicologia da Educação, n. 40, p. 77-85, 2015. https://doi.org/10.5935/2175$\underline{3520.20150006}$

\author{
Maria Luiza Gava Schmidt \\ Assis, São Paulo, Brasil \\ Psicóloga. Doutora em Saúde Coletiva pela Faculdade de Ciências Médicas - Unicamp. Pós- \\ Doutorado pela Faculdade de Saúde Pública - USP. Docente do Curso de Graduação em Psicologia \\ e Supervisora de Estágio, Departamento de Psicologia Social, Faculdade de Ciências e Letras - \\ Unesp, Câmpus de Assis/SP. \\ E-mail: mlschmidt@uol.com.br \\ Lattes: http://lattes.cnpq.br/2100242063714231
}

\title{
Larissa Prato Santos
}

Assis, São Paulo, Brasil

Psicóloga. Estagiária da ênfase Princípios e Métodos da Terapia Cognitivo-Comportamental e A Prática Clínica na Abordagem Cognitivo-Comportamental e da ênfase Processos Saúde-Doença no Trabalho com foco em Psicologia e Saúde no Trabalho. Bolsista de Iniciação Científica FAPESP no campo da Saúde do Trabalhador.

E-mail: larissa.prato@unesp.br

Lattes: http://lattes.cnpq.br/8252326688072489

\section{Letícia Piffer}

\section{Assis, São Paulo, Brasil}

Graduanda em Psicologia na Universidade Estadual Paulista, e Coordenadora de gestão de pessoas na Humanus, que é uma empresa júnior, vinculada ao curso de psicologia da Universidade Estadual Paulista Júlio de Mesquita Filho.

E-mail: leticia.piffer@unesp.br

Lattes: http://lattes.cnpq.br/8219322581499670 


\section{Venâncio Paiola Tonon}

Assis, São Paulo, Brasil

Graduado em Psicologia na Universidade Estadual Paulista, bolsista FAPESP, desenvolveu o projeto de iniciação científica "O Conceito de Drama como Articulador da Crítica dos Fundamentos da Psicologia, de Georges Politzer (1928)". Com bolsa do programa Mitacs Globalink Research Internship, realizou estágio de pesquisa na McGill University, em Montreal, Canadá, onde integrou o Knowledge Sharing Research Group (Knowah). Foi bolsista PIBIC - CNPq entre 2017 e 2019. Realizou intercâmbio institucional na University of Victoria, em Victoria, Canadá.

E-mail: paiola.tonon@unesp.br

Lattes: http://lattes.cnpq.br/8789253103971401

\section{João Massuda Junior}

Campo Grande, Mato Grosso do Sul, Brasil

Administrador e Mestre em Administração pela UFMS, Especialista em Administração da Informação pela UNIDERP e Doutor em Psicologia pela UCDB. Professor Colaborador do IPqHCFMUSP. Atua como professor no Instituto Federal de Mato Grosso do Sul (IFMS) e Membro do Laboratório de Saúde Mental e Qualidade de Vida no Trabalho (UCDB/CNPq).

E-mail: leticia.piffer@unesp.br

Lattes: http://lattes.cnpq.br/8219322581499670

João Areosa

Lisboa, Portugal

Professor Adjunto na Escola Superior de Ciências Empresariais( ESCE-IPS), Instituto Politécnico de Setúbal, Portugal. Pesquisador no Centro Interdisciplinar em Ciências Sociais ( CISC.NOVA) da Universidade Nova Lisboa, Portugal.

E-mail: joao.s.areosa@gmail.com

Lattes: http://lattes.cnpq.br/1175949950915388

\section{Recebimento: 15/05/2021}

Aprovação: 16/06/2021

\section{Q.Code}

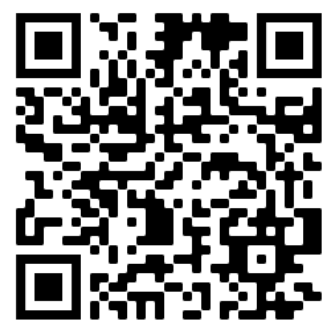

\section{Editores-Responsáveis}

Dr. Enéas de Araújo Arrais Neto, Universidade Federal do Ceará, UFC, Ceará, Brasil

Dr. Sebastien Pesce, Universidade de Orléans, França 